Supporting information for

\title{
Eukaryotic TYW1 Is A Radical SAM Flavoenzyme
}

Anthony P. Young and Vahe Bandarian*

Department of Chemistry, University of Utah, Salt Lake City, Utah 84112, United States

* Corresponding author: (VB) vahe@chem.utah.edu

Table of Contents

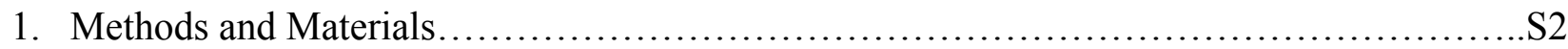

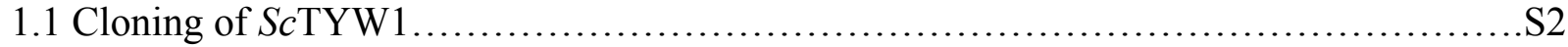

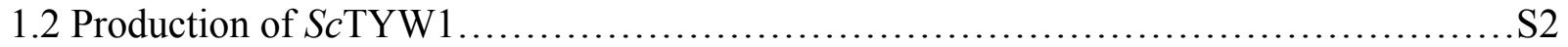

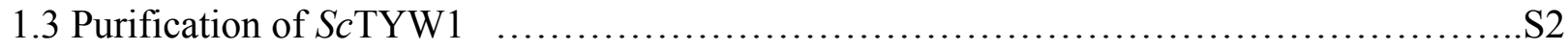

1.4 Production and purification of TEV protease ........................................ 3

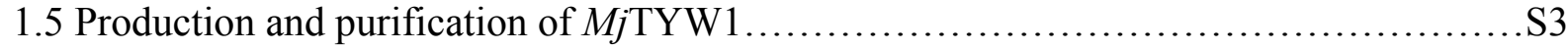

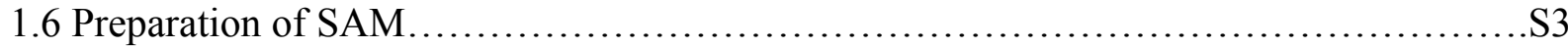

1.7 Purification of soluble RNA from S. cerevisiae YPL207w deletion strain..............S4

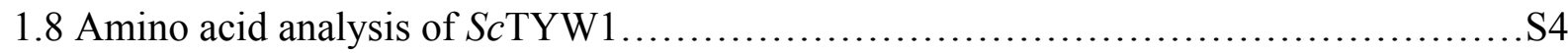

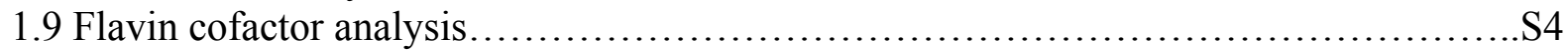

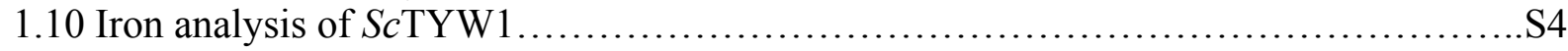

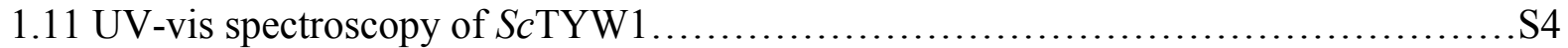

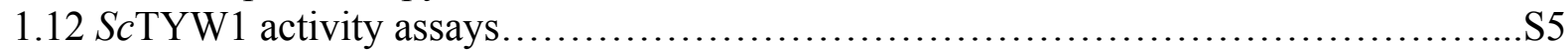

1.13 ScTYW1 assays with varying FMN concentrations.............................. 5

$1.14 \mathrm{ScTYW1}$ assays with different reductants....................................... 5

1.15 Comparison of MjTYW1 and ScTYW1 activity in the presence of different

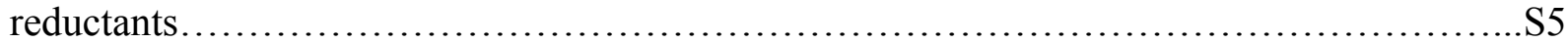

1.16 Reduction of FMN with NADPH in solution ...................................... 5

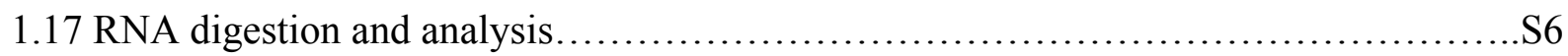

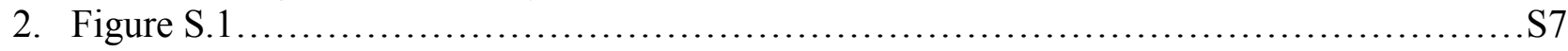

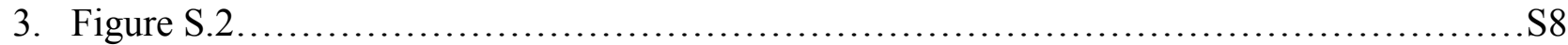

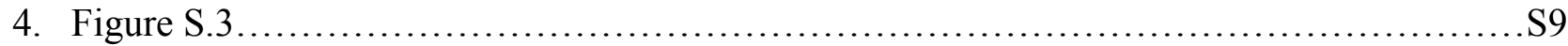

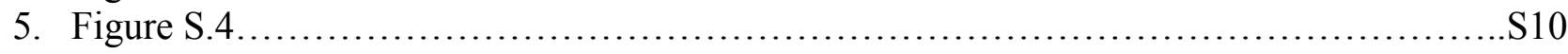

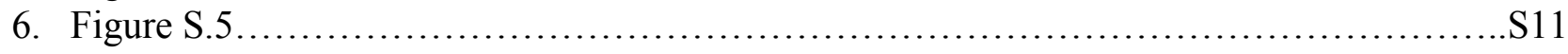

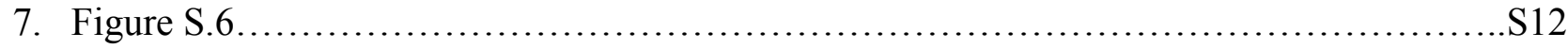

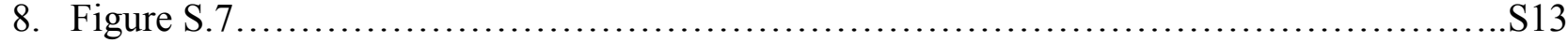

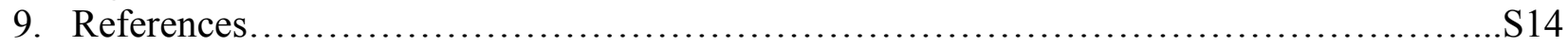




\section{Methods and Materials}

1.1 Cloning of $\boldsymbol{S c T Y W 1 . ~ T h e ~ g e n e , ~ c o d o n ~ o p t i m i z e d ~ f o r ~ e x p r e s s i o n ~ i n ~} E$. coli, corresponding to TYW1 (YPL207W) from $S$. cerevisiae was obtained from GenScript in a pUC57 vector. The gene sequence is shown in Fig S.1. The portion of the sequence coding for amino acids 46-810 was PCR amplified using the forward primer 5'-AAAAAAAACATATGGGTTCACAGGACTCGC-3' and the reverse primer 5'AAAAAAAAGCTTATCAGGCCGGAATCGGCG-3' with the italicized sequences encoding NdeI (forward primer) and HindIII (reverse primer) restriction sites (italic). The PCR product and pET28JT vector (1) were digested with NdeI, HindIII, and CIP, and then ligated using T4 DNA ligase to form plasmid pAY788. This plasmid contains an N terminal Histag followed by a Tobacco Etch Virus nuclearinclusion-a endopeptidase (TEV) cleavage site and then ScTYW1. The resulting DNA sequence of the gene and tag are shown in Fig S.2. The protein sequence is shown in Fig S.3. With this construct, upon cleavage by TEV we obtained a protein with residues QGHM at the N-terminus, which starts at amino acid 46 of YPL207W.

1.2 Production of $\boldsymbol{S c T Y W 1 . ~ E . ~ c o l i ~ B L 2 1 - D E 3 ~ p h a g e ~ T 1 ~ r e s i s t a n t ~ c e l l s ~ ( N E B ~ C 2 5 2 7 ) ~ w e r e ~ c o - ~}$ transformed with pAY788 and pPH151, which encodes the E. coli sufABCDSE operon (2), and plated on a Lysogeny broth (LB), Lennox formulation, agar plate containing $34 \mu \mathrm{g} / \mathrm{mL}$ chloramphenicol and kanamycin. A single colony was picked and used to inoculate a $125 \mathrm{~mL}$ culture of LB, containing 34 $\mu \mathrm{g} / \mathrm{mL}$ each of chloramphenicol and kanamycin, and grown overnight at $37^{\circ} \mathrm{C}$.

Ten $\mathrm{mL}$ of the overnight culture was used to inoculate twelve $2.8 \mathrm{~L}$ Fernbach flasks containing $1 \mathrm{~L}$ of Terrific broth (TB), $34 \mu \mathrm{g} / \mathrm{mL}$ each of kanamycin and chloramphenicol, and 1x of a trace metal solution (3). The cells were grown at $37{ }^{\circ} \mathrm{C}$ with shaking at $175 \mathrm{rpm}$ to an $\mathrm{OD}_{600} \sim 0.6$, at which point the temperature was reduced to $18{ }^{\circ} \mathrm{C}$. One hour later solid riboflavin $(\sim 200 \mathrm{mg})$, isopropyl $\beta-\mathrm{D}-1-$ thiogalactopyranoside $\left(500 \mu \mathrm{M}\right.$ final concentration), and iron(III)chloride $\left(\mathrm{FeCl}_{3}\right)(50 \mu \mathrm{M}$ final concentration) were added. The shaking speed was reduced further to $125 \mathrm{rpm}$ and the growth continued for $\sim 16 \mathrm{~h}$. The cells were harvested by centrifugation at 5,000 xg and flash frozen. The typical yield is $\sim 7$ $\mathrm{g} / \mathrm{L}$ of culture.

1.3 Purification of $\boldsymbol{S c T Y W 1}$ (UniProtKB Q08960). The purification was carried out in a Coy chamber $\left(97 \% \mathrm{~N}_{2}, 3 \% \mathrm{H}_{2}\right)$. The cell paste from $12 \mathrm{~L}$ of growth $(\sim 80 \mathrm{~g})$ was resuspended in $50 \mathrm{mM}$ potassium phosphate (KPi) ( $\mathrm{pH} 7.4$ ) buffer containing $0.5 \mathrm{M}$ potassium chloride $(\mathrm{KCl}), 50 \mathrm{mM}$ imidazole, $1 \mathrm{mM}$ phenylmethylsulfonyl fluoride, $1 \mathrm{mM} \mathrm{FMN}$, and $100 \mu \mathrm{g} / \mathrm{mL}$ lysozyme. Cells were lysed using a Branson sonifier at $50 \%$ amplitude for 25 min total with $15 \mathrm{~s}$ bursts of sonication, followed by $60 \mathrm{~s}$ breaks while stirring on ice to avoid excess heating of the solution. The cell lysate was clarified by centrifugation at $35,000 \mathrm{xg}$ for $1 \mathrm{~h}$. at $4{ }^{\circ} \mathrm{C}$.

Using an AKTA prime plus, the clarified lysate was loaded onto four $5 \mathrm{~mL}$ His Trap FF columns connected in series, charged with $\mathrm{Ni}^{2+}$ and equilibrated in $50 \mathrm{mM} \mathrm{KPi}(\mathrm{pH} \mathrm{7.4)} \mathrm{buffer} \mathrm{containing} 0.5 \mathrm{KCl}$ and 50 $\mathrm{mM}$ imidazole. The columns were washed with the same buffer and bound protein was eluted via a step gradient to equilibration buffer containing $0.5 \mathrm{M}$ imidazole. Brown/black fractions were pooled, solid dithiothreitol (DTT) was added ( $2 \mathrm{mM}$ final concentration) along with $10 \mathrm{mg}$ of TEV protease and stirred at room temperature for $4 \mathrm{~h}$. 
Precipitated protein was removed by centrifugation at $35,000 \mathrm{xg}$ at $4{ }^{\circ} \mathrm{C}$ for $10 \mathrm{~min}$ and the clarified protein solution was desalted into $50 \mathrm{mM} \mathrm{KPi} \mathrm{(pH} \mathrm{7.4)} \mathrm{buffer} \mathrm{containing} 0.5 \mathrm{KCl}$ and $50 \mathrm{mM}$ imidazole using a Sephadex G25 column (18 X $2.5 \mathrm{~cm})$. The protein was passed back over the four serially connected HisTrap columns equilibrated in $50 \mathrm{mM} \mathrm{KPi} \mathrm{(pH} \mathrm{7.4)} \mathrm{buffer} \mathrm{containing} 0.5 \mathrm{KCl}$ and $50 \mathrm{mM}$ imidazole. The flowthrough was collected, flash-frozen in liquid nitrogen, and stored at $-80{ }^{\circ} \mathrm{C}$.

ScTYW1 was further purified by anion exchange chromatography. For this step, the protein solution from above was thawed, solid FMN was added to a final concentration of $0.5 \mathrm{mM}$, followed by a 10 -fold dilution by the addition of $20 \mathrm{mM}$ piperazine-N,N'-bis(2-ethanesulfonic acid)-sodium hydroxide ( $\mathrm{pH}$ 7.4) (PIPES-NaOH) buffer to decrease the $\mathrm{KCl}$ concentration to $\sim 50 \mathrm{mM}$ prior to loading onto a Q-Sepharose FF column (10 X $1.7 \mathrm{~cm})$ equilibrated in $20 \mathrm{mM}$ PIPES-NaOH (pH 7.4). The column was washed with the loading buffer and the bound protein was eluted with a $0.25 \mathrm{~L}$ gradient to $20 \mathrm{mM}$ PIPES-NaOH $(\mathrm{pH}$ 7.4) buffer containing $0.5 \mathrm{M} \mathrm{KCl}$. Fractions containing protein were identified via SDS-PAGE and were pooled and concentrated to approximately $20 \mathrm{~mL}$ using an Amicon stirred cell under nitrogen gas pressure. The protein was flash-frozen in liquid nitrogen and stored at $-80{ }^{\circ} \mathrm{C}$. Prior to reconstitution, the protein was thawed and desalted into $50 \mathrm{mM}$ PIPES-NaOH (pH 7.4) buffer containing $0.5 \mathrm{M} \mathrm{NaCl}$ and $2 \mathrm{mM}$ DTT using the Sephadex G25 column. A Bradford protein assay with BSA as standard (ThermoScientific) was used to determine the protein concentration. Tenfold molar excess of $\mathrm{FeCl}_{3}$, sodium sulfide, and a fivefold molar excess of FMN, dissolved in water, were added to the solution while stirring and the solution was incubated at room temperature for $4 \mathrm{~h}$. Precipitated protein was removed by centrifugation and the solution was desalted into $50 \mathrm{mM}$ PIPES-NaOH (pH 7.4) buffer containing $0.15 \mathrm{M} \mathrm{KCl}$ and 2 mM DTT using the Sephadex G25 column.

The final gel filtration step in the purification removes high molecular weight components, which are often observed after reconstitution. In this step, the protein was concentrated to $\sim 3 \mathrm{~mL}$ and loaded onto a Sephacryl S-300 HR column $(60 \times 2.5 \mathrm{~cm})$ equilibrated in $50 \mathrm{mM}$ PIPES-NaOH $(\mathrm{pH} 7.4)$ buffer containing $0.15 \mathrm{M} \mathrm{KCl}$ and $2 \mathrm{mM}$ DTT. The fractions containing protein were identified via color and SDS-PAGE and concentrated to $\sim 3 \mathrm{~mL}$. Aliquots were flash-frozen in liquid nitrogen and stored at -80 ${ }^{\circ} \mathrm{C}$. The concentration of this protein was typically $\sim 150 \mu \mathrm{M}$ as determined by Bradford assay with BSA as standard.

1.4 Production and purification of TEV protease. TEV protease was produced and purified as described previously $(1,4)$. The stock concentration was determined to be $93 \mu \mathrm{M}$.

1.5 Production and purification of $M$. jannaschii TYW1 (MjTYW1) (UniProtKB Q57705). MjTYW1 was produced and purified as described previously (4).

1.6 Preparation of SAM. SAM was synthesized as described previously $(4,5)$.

1.7 Purification of soluble RNA from $S$. cerevisiae YPL207w deletion strain. RNA was purified from S. cerevisiae YPL207w deletion strain (YSC1-21-547084 Thermo Scientific) as previously described (4), with a method adapted from (6). 
1.8 Amino acid analysis of $S c T Y W 1$. Amino acid analysis of the protein was carried out at the UC Davis Genomics Center revealing a correction factor of 0.77 to relate the Bradford assays to amino acid content.

1.9 Flavin cofactor analysis. Protein was precipitated by the addition of $30 \%(\mathrm{w} / \mathrm{v})$ trichloroacetic acid (TCA) in water to a final concentration of $10 \%(\mathrm{v} / \mathrm{v})$. Precipitated protein was removed by centrifugation and an aliquot of the supernatant was analyzed by a Thermo Vanquish UHPLC and the analytes were separated using a Thermo Hypersil gold C18 column $(150 \times 2.1 \mathrm{~mm}) 1.9 \mu$ particle size.

The UHPLC was run with a flow rate of $0.2 \mathrm{~mL} / \mathrm{min}$ with buffer A consisting of $0.1 \%(\mathrm{v} / \mathrm{v}) \mathrm{TFA}(\mathrm{v} / \mathrm{v})$ water and buffer B consisting of $0.1 \%$ TFA $(\mathrm{v} / \mathrm{v})$ in acetonitrile. The separation program was as follows: 0-6 min, 0\% B; 6-30 min, 0-100\% B; 30.1-35 min, 100\% B; 35.1-39.8 min, 0\% B. UV-vis absorbance were measured at 375 and $450 \mathrm{~nm}$.

The identity of the flavin cofactor was verified by comparison of retention times with FMN and FAD standards. The concentration of the FMN cofactor was determined by comparing the area of the peak at 375 and $450 \mathrm{~nm}$ to a standard curve of FMN. The FMN standard was dissolved in water and acidified by the addition of $30 \%(\mathrm{w} / \mathrm{v})$ TCA to a final concentration of $10 \%(\mathrm{v} / \mathrm{v})$ and the concentration determined by UV-visible spectroscopy on an Agilent $8454 \mathrm{UV}$-visible spectrophotometer at $445 \mathrm{~nm}$ with $\varepsilon_{445} 12,500$ $\mathrm{M}^{-1} \mathrm{~cm}^{-1}$.

This was performed on three different preparations of ScTYW1.

1.10 Iron analysis of ScTYW1. ScTYW1 was diluted to a concentration of $1 \mu \mathrm{M}$ by addition of $1 \%$ $(\mathrm{v} / \mathrm{v})$ nitric acid. Iron concentration was determined by inductively coupled plasma mass spectrometry at the ICP-MS metals and strontium isotope facility within the Department of Geology and Geophysics at the University of Utah.

This was performed on three different preparations of ScTYW1.

1.11 UV-vis spectroscopy of ScTYW1. All measurements were recorded on an Agilent 8453 UV-visible spectrophotometer inside a Coy anaerobic chamber $\left(97 \% \mathrm{~N}_{2}, 3 \% \mathrm{H}_{2}\right)$. All samples were diluted with 50 $\mathrm{mM}$ PIPES-NaOH (pH 7.4) buffer containing $150 \mathrm{mM} \mathrm{KCl}$ and $2 \mathrm{mM}$ DTT. The protein concentration in the oxidized and reduced spectra is $10 \mu \mathrm{M}$. The protein was reduced by the addition of dithionite (final concentration of $0.1 \mathrm{mM}$ ) and the spectrum recorded. The spectrum of the flavin cofactor was obtained by addition of $12 \mu \mathrm{L}$ of $30 \%$ TCA to $120 \mu \mathrm{L}$ of $25 \mu \mathrm{M}$ ScTYW1. Protein was removed by centrifugation and an absorbance spectrum of the supernatant was recorded.

1.12 Sc TYW1 activity assays. All assays were setup in a Coy chamber $\left(97 \% \mathrm{~N}_{2}, 3 \% \mathrm{H}_{2}\right)$ using anaerobic solutions. Assays were carried out in $50 \mathrm{mM}$ PIPES-NaOH (pH 7.4) buffer containing $2 \mathrm{mM}$ SAM, 10

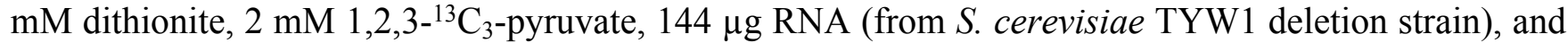
$15 \mu \mathrm{M}$ ScTYW1 in a final volume of $100 \mu \mathrm{L}$. Samples were incubated at $30{ }^{\circ} \mathrm{C}$ for $4 \mathrm{~h}$. and were quenched by flash freezing in liquid nitrogen. RNA was then extracted and analyzed as described below. This assay was performed in duplicate. 
1.13 ScTYW1 assays with varying FMN concentrations. All assays were setup in a Coy chamber ( $97 \%$ $\mathrm{N}_{2}, 3 \% \mathrm{H}_{2}$ ) using anaerobic solutions. Assays were carried out in $50 \mathrm{mM}$ PIPES-NaOH (pH 7.4) buffer

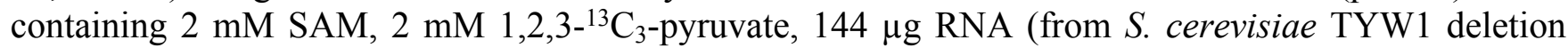
strain), $2 \mathrm{mM}$ NADPH and $15 \mu \mathrm{M}$ ScTYW1. The following concentrations of FMN were added: $0,0.5$, $1,2.5,5,7.5,10,20,40$, and $60 \mu \mathrm{M}$. This was in a final volume of $100 \mu \mathrm{L}$ and samples were incubated at $30{ }^{\circ} \mathrm{C}$ for $4 \mathrm{~h}$. The samples were quenched and analyzed as described below. This assay was performed in triplicate.

1.14 ScTYW1 assays with different reductants. All assays were setup in a Coy chamber $\left(97 \% \mathrm{~N}_{2}, 3 \%\right.$ $\mathrm{H}_{2}$ ) using anaerobic solutions. Assays were carried out in $50 \mathrm{mM}$ PIPES-NaOH (pH 7.4) buffer containing 2 mM SAM, 2 mM 1,2,3-13 $\mathrm{C}_{3}$-pyruvate, $144 \mu \mathrm{g}$ RNA (from $S$. cerevisiae TYW1 deletion strain), and 15 $\mu \mathrm{M}$ ScTYW1 in a final volume of $400 \mu \mathrm{L}$. The reductants were at the following concentrations when present: dithionite $-10 \mathrm{mM}, \mathrm{NADPH}-2 \mathrm{mM}, \mathrm{NADH}-2 \mathrm{mM}, \mathrm{FAD}-20 \mu \mathrm{M}$, and FMN $-20 \mu \mathrm{M}$. The mixtures were incubated at $30^{\circ} \mathrm{C}$, and aliquots $(100 \mu \mathrm{L})$ were removed at 1,2 , and $4 \mathrm{~h}$. The aliquots were quenched by flash freezing in liquid nitrogen and storing at $-20^{\circ} \mathrm{C}$ until the RNA was extracted as described below. This assay was performed a minimum of three times

1.15 Comparison of MjTYW1 and $S c$ TYW1 activity in the presence of different reductants. All assays were setup in a Coy chamber $\left(97 \% \mathrm{~N}_{2}, 3 \% \mathrm{H}_{2}\right)$ using anaerobic solutions. These samples contained $50 \mathrm{mM}$ PIPES-NaOH (pH 7.4) buffer containing $2 \mathrm{mM} \mathrm{SAM}, 1,2,3-{ }^{13} \mathrm{C}_{3}$-pyruvate, $144 \mu \mathrm{g}$ RNA (from $S$. cerevisiae TYW1 deletion strain) and $15 \mu \mathrm{M}$ of either ScTYW1 or MjTYW1. The reductants were at the following concentrations when present: dithionite - $10 \mathrm{mM}, \mathrm{NADPH}-2 \mathrm{mM}, \mathrm{NADH}-2 \mathrm{mM}, \mathrm{FAD}-$ $20 \mu \mathrm{M}$, and FMN $-20 \mu \mathrm{M}$. The assays containing ScTYW1 were incubated at $30^{\circ} \mathrm{C}$ and those containing MjTYW1 at $50^{\circ} \mathrm{C}$. These were $100 \mu \mathrm{L}$ reactions and were quenched as described below after $4 \mathrm{~h}$. This assay was performed in triplicate.

1.16 Reduction of FMN with NADPH in solution. All measurements were recorded on an Agilent 8453 UV-visible spectrophotometer inside a Coy anaerobic chamber $\left(97 \% \mathrm{~N}_{2}, 3 \% \mathrm{H}_{2}\right)$ in the dark. One chamber of a mixing cuvette contained $4 \mathrm{mM}$ NADPH in $50 \mathrm{mM}$ PIPES-KOH (pH 7.4) and the other chamber an equal volume of $40 \mu \mathrm{M}$ FMN in water. The spectrophotometer was blanked with the NADPH solution. The reaction was initiated by inversion of the cuvette and the absorbance spectrum recorded at $0,10,20$, and $30 \mathrm{~min}$.

1.17 RNA digestion and analysis. RNA was extracted from assays and digested to the nucleoside level as described previously (4) with one exception. The $\mathrm{P} 1$ digestion took place at $45{ }^{\circ} \mathrm{C}$ for $14 \mathrm{~h}$. Prior to analysis via LC-MS, $60 \mu \mathrm{L}$ of digested nucleosides was combined with $5 \mu \mathrm{L}$ of $1 \mu \mathrm{M} 2^{\prime}$-deoxy-4demethylwyosine (dimG-14), and $63 \mu \mathrm{L}$ was injected onto a Thermo Vanquish UHPLC connected in series to a Q-Exactive mass spectrometer.

Analytes were separated using a Thermo Hypersil gold C18 column $(150 \times 2.1 \mathrm{~mm}) 1.9 \mu$ particle size. The separation program was described previously(4). The Q Exactive mass spectrometer was operated in positive ion mode, with a resolution of 70,000 and a scan range of 300 to $400 \mathrm{~m} / \mathrm{z}$. 


\section{Figure S.1.}

CATATGGACGGTTTTCGTGTGGCGGGTGCCCTGGTCGTTGGTGCTCTGACGGCGGCGTATCTGTACTTC GGCGGTCGCTTCTCGATTGCCCTGGTCATTATCGTGGGCTATGGTATCTACTGCAACGAAGCATCCGGC GGTTCACAGGACTCGCAAGAAAAACTGGATCTGAATAAGCAGCAGAAAAAACCGTGCTGTAGTGACAAA AAGATTGCTGATGGCGGTAAAAAGACCGGCGGTTGCTGTTCCGATAAAAAGAACGGCGGTGGCAAGGGT GGCGGTTGCTGTAGCTCTAAAGGCGGTAAAAAGGGCGGTTGCTGTAGTTCCAAAGGCGGTAAAAAGGGC GGTTGTTGTTCATCGAAAAAGAACATCGGCGACAACGAAAATACCGCAACGGAAGTCGAAAAAGCTGTG AATTATCCGGTGACCGTTGATTTTACGGAAGTTTTCCGTAAACCGACCAAAAAGCGCAGCTCTACGCCG AAGGTCTTTAGTAAAAACAGTTCCTCAAATTCCCGTGTGGGCAAAAAGCTGTCCGTTTCAAAAAAGATT GGCCCGGATGGTCTGATCAAAAGCGCGCTGACCATTTCTAATGAAACGCTGCTGTCGAGCCAGATTTAT GTGCTGTACTCTAGTCTGCAGGGTGCGGCCAGTAAGGCAGCTAAATCCGTTTACGACAAGCTGAAAGAA CTGGATGAACTGACCAACGAACCGAAACTGCTGAATCTGGATGACCTGAGCGATTTTGATGACTATTTC ATCAACGTCCCGGTGGAAAATGCGCTGTATGTTCTGGTCCTGCCGTCTTACGATATTGACTGTCCGCTG GATTACTTTCTGCAGACCCTGGAAGAAAACGCCAATGATTTTCGTGTGGACAGCTTCCCGCTGCGCAAA CTGGTTGGCTATACCGTCCTGGGCCTGGGTGACTCGGAAAGCTGGCCGGAAAAATTTTGCTACCAGGCA AAGCGTGCTGATCATTGGATCAGCCGTCTGGGCGGTCGTCGCATTTTCCCGCTGGGCAAGGTTTGTATG AAAACCGGCGGTTCAGCAAAAATTGATGAATGGACCTCGCTGCTGGCTGAAACGCTGAAAGATGACGAA CCGATTATCTATGAATACGATGAAAACGCGGACAGCGAAGAAGATGAAGAAGAAGGCAATGGTTCTGAT GAACTGGGCGATGTGGAAGACATCGGCGGTAAAGGCTCAAACGGCAAGTTTTCGGGTGCGGACGAAATT AAACAGATGGTTGCCAAGGATAGCCCGACCTATAAGAATCTGACGAAACAAGGCTACAAGGTTATCGGC TCTCATAGTGGTGTCAAAATTTGCCGTTGGACCAAGAACGAACTGCGCGGCAAAGGTAGCTGTTACAAA AAGTCTCTGTTCAACATCGCGTCCTCACGTTGCATGGAACTGACCCCGTCACTGGCCTGTTCGAGCAAA TGCGTGTTCTGTTGGCGTCACGGCACGAACCCGGTCTCGAAAAATTGGCGCTGGGAAGTGGATGAACCG GAATATATTCTGGAAAACGCGCTGAAGGGTCATTACAGCATGATCAAACAGATGCGCGGCGTTCCGGGT GTCATTGCAGAACGTTTTGCAAAAGCGTTTGAAGTTCGCCACTGCGCTCTGAGCCTGGTCGGCGAACCG ATCCTGTACCCGCATATCAACAAGTTCATCCAGCTGCTGCACCAAAAAGGTATTACCAGTTTCCTGGTG TGTAACGCGCAGCATCCGGAAGCCCTGCGTAATATCGTGAAAGTTACGCAACTGTATGTCTCTATTGAT GCCCCGACCAAAACGGAACTGAAAAAGGTGGACCGTCCGCTGTACAAAGATTTTTGGGAACGCATGGTG GAATGCCTGGAAATTCTGAAAACCGTTCAGAACCACCAACGTACCGTCTTTCGCCTGACGCTGGTGAAA GGCTTCAATATGGGTGACGTTAGTGCGTATGCCGATCTGGTTCAGCGTGGTCTGCCGGGTTTTATCGAA GTGAAAGGCGCAACCTTCTCCGGTTCTAGTGATGGCAACGGTAATCCGCTGACGATGCAGAACATTCCG TTCTACGAAGAATGCGTGAAGTTCGTTAAAGCCTTCACCACGGAACTGCAACGTCGCGGTCTGCATTAC GACCTGGCGGCCGAACATGCACACAGCAACTGTCTGCTGATCGCTGATACCAAGTTTAAAATTAATGGC GAATGGCATACGCACATTGATTTCGACAAATTTTTCGTGCTGCTGAACTCTGGTAAAGACTTCACCTAT ATGGATTACCTGGAAAAAACGCCGGAATGGGCGCTGTTTGGCAACGGCGGTTTCGCCCCGGGTAATACC CGTGTTTATCGCAAAGATAAAAAGAAACAGAATAAAGAAAACCAAGAAACGACCACCCGTGAAACCCCG CTGCCGCCGATTCCGGCCTGATAAGCTT

Figure S.1. DNA sequence of codon optimized ScTYW1. The NdeI and HindIII sites are underlined. 


\section{Figure S.2.}

ATGGGCAGCAGC CATCATCATCATCATCACAGCAGCGAGAACCTGTACTTCCAGGGCCATATGGGTTCA CCGGAGGACTCGCAAGAAAAACTGGATCTGAATAAGCAGCAGAAAAAACCGTGCTGTAGTGACAAAAAG ATTGCTGATGGCGGTAAAAAGACCGGCGGTTGCTGTTCCGATAAAAAGAACGGCGGTGGCAAGGGTGGC GGTTGCTGTAGCTCTAAAGGCGGTAAAAAGGGCGGTTGCTGTAGTTCCAAAGGCGGTAAAAAGGGCGGT TGTTGTTCATCGAAAAAGAACATCGGCGACAACGAAAATACCGCAACGGAAGTCGAAAAAGCTGTGAAT TATCCGGTGACCGTTGATTTTACGGAAGTTTTCCGTAAACCGACCAAAAAGCGCAGCTCTACGCCGAAG GTCTTTAGTAAAAACA GTTCCTCAAATTCCCGTGTGGGCAAAAAGCTGTCCGTTTCAAAAAAGATTGGC CCGGATGGTCTGATCAAAAGCGCGCTGACCATTTCTAATGAAACGCTGCTGTCGAGCCAGATTTATGTG CTGTACTCTAGTCTGCAGGGTGCGGCCAGTAAGGCAGCTAAATCCGTTTACGACAAGCTGAAAGAACTG GATGAACTGACCAACGAACCGAAACTGCTGAATCTGGATGACCTGAGCGATTTTGATGACTATTTCATC AACGTCCCGGTGGAAAATGCGCTGTATGTTCTGGTCCTGCCGTCTTACGATATTGACTGTCCGCTGGAT TACTTTCTGCAGACCCTGGAAGAAAACGCCAATGATTTTCGTGTGGACAGCTTCCCGCTGCGCAAACTG GTTGGCTATACCGTCCTGGGCCTGGGTGACTCGGAAAGCTGGCCGGAAAAATTTTGCTACCAGGCAAAG CGTGCTGATCATTGGATCAGCCGTCTGGGCGGTCGTCGCATTTTCCCGCTGGGCAAGGTTTGTATGAAA ACCGGCGGTTCAGCAAAAATTGATAATGGACCTCGCTGCTGGCTGAAACGCTGAAAGATGACGAACCG ATtATCTATGAATACGATGAAAACGCGGACAGCGAAGAAGATGAAGAAGAAGGCAATGGTTCTGATGAA CTGGGCGATGTGGAAGACATCGGCGGTAAAGGCTCAAACGGCAAGTTTTCGGGTGCGGACGAAATTAAA CAGATGGTTGCCAAGGATAGCCCGACCTATAAGAATCTGACGAAACAAGGCTACAAGGTTATCGGCTCT CATAGTGGTGTCAAAATTTGCCGTTGGACCAAGAACGAACTGCGCGGCAAAGGTAGCTGTTACAAAAAG TCTCTGTTCAACATCGCGTCCTCACGTTGCATGGAACTGACCCCGTCACTGGCCTGTTCGAGCAAATGC GTGTTCTGTTGGCGTCACGGCACGAACCCGGTCTCGAAAAATTGGCGCTGGGAAGTGGATGAACCGGAA TATATTCTGGAAAACGCGCTGAAGGGTCATTACAGCATGATCAAACAGATGCGCGGCGTTCCGGGTGTC ATTGCAGAACGTTTTGCAAAAGCGTTTGAAGTTCGCCACTGCGCTCTGAGCCTGGTCGGCGAACCGATC CTGTACCCGCATATCAACAAGTTCATCCAGCTGCTGCACCAAAAAGGTATTACCAGTTTCCTGGTGTGT AACGCGCAGCATCCGGAAGCCCTGCGTAATATCGTGAAAGTTACGCAACTGTATGTCTCTATTGATGCC CCGACCAAAACGGAACTGAAAAAGGTGGACCGTCCGCTGTACAAAGATTTTTGGGAACGCATGGTGGAA TGCCTGGAAATTCTGAAAACCGTTCAGAACCACCAACGTACCGTCTTTCGCCTGACGCTGGTGAAAGGC TTCAATATGGGTGACGTTAGTGCGTATGCCGATCTGGTTCAGCGTGGTCTGCCGGGTTTTATCGAAGTG AAAGGCGCAACCTTCTCCGGTTCTAGTGATGGCAACGGTAATCCGCTGACGATGCAGAACATTCCGTTC TACGAAGAATGCGTGAAGTTCGTTAAAGCCTTCACCACGGAACTGCAACGTCGCGGTCTGCATTACGAC CTGGCGGCCGAACATGCACACAGCAACTGTCTGCTGATCGCTGATACCAAGTTTAAAATTAATGGCGAA TGGCATACGCACATTGATTTCGACAAATTTTTGTGCTGCTGAACTCTGGTAAAGACTTCACCTATATG GATTACCTGGAAAAAACGCCGGAATGGGCGCTGTTTGGCAACGGCGGTTTCGCCCCGGGTAATACCCGT GTTTATCGCAAAGATAAAAAGAAACA GAATAAA GAAAACCAAGAAACGACCACCCGTGAAACCCCGCTG CCGCCGATTCCGGCCTGATAAGCTT

Figure S.3. The DNA sequence of the gene expressed in this study. The restriction sites used to clone the gene into the vector are underlined. The His 6 -tag is shown in italics. The TEV protease site is shown in bold. 


\section{Figure S.3.}

MGSSHHHHHHSSENLYFQGHMGSPEDSQEKLDLNKQQKKPCCSDKKIADGGKKTGGCCSDKKNGGGKGG GCCSSKGGKKGGCCSSKGGKKGGCCSSKKNIGDNENTATEVEKAVNYPVTVDFTEVERKPTKKRSSTPK VESKNSSSNSRVGKKLSVSKKIGPDGLIKSALTISNETLLSSQIYVLYSSLQGAASKAAKSVYDKLKEL DELTNEPKLLNLDDLS DFDDYFINVPVENALYVLVLPSYDIDCPLDYFLQTLEENANDFRVDSFPLRKL VGYTVLGLGDSESWPEKFCYQAKRADHWISRLGGRRIFPLGKVCMKTGGSAKIDEWTSLLAETLKDDEP I IYEYDENADSEEDEEEGNGSDELGDVEDIGGKGSNGKFSGADEIKQMVAKDSPTYKNLTKQGYKVIGS HSGVKICRWTKNELRGKGSCYKKSLFNIASSRCMELTPSLACSSKCVFCWRHGTNPVSKNWRWEVDEPE YILENALKGHYSMIKQMRGVPGVIAERFAKAFEVRHCALSLVGEP I LYPH INKF IQLLHQKGITSELVC NAQHPEALRNIVKVTQLYVS IDAPTKTELKKVDRPLYKDFWERMVECLEILKTVQNHQRTVERLTLVKG FNMGDVSAYADLVQRGLPGFIEVKGATFSGSSDGNGNPLTMQNI PFYEECVKFVKAFTTELQRRGLHYD LAAEHAHSNCLLIADTKFKINGEWHTH IDFDKF FVLLNSGKDFTYMDYLEKTPEWALFGNGGFAPGNTR VYRKDKKKQNKENQETTTRETPLPPIPA

Figure S.3. The protein sequence of ScTYW1 used in this study. The portion removed following TEV cleavage is shown underlined. 


\section{Figure S.4.}

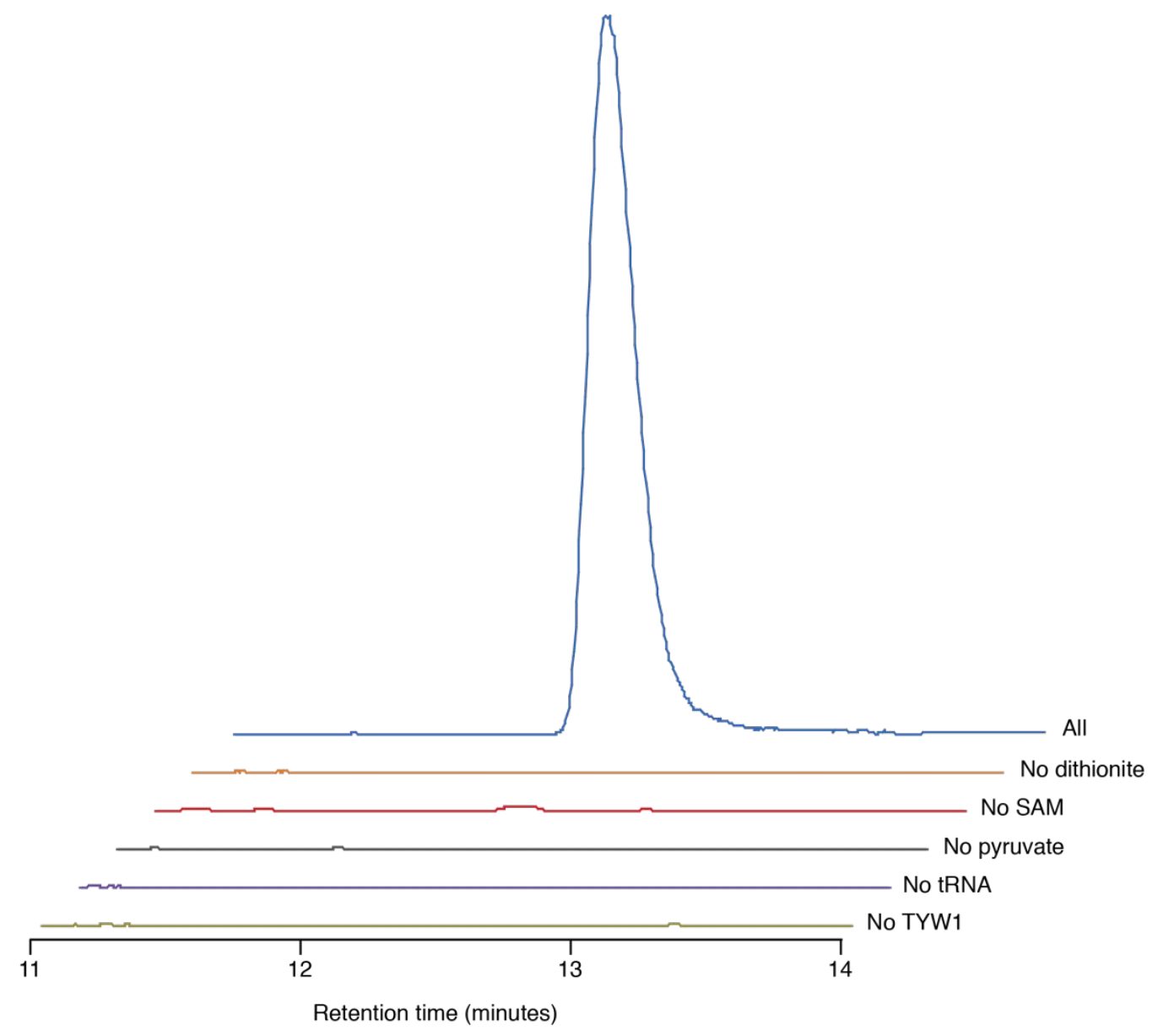

Figure S.4. ScTYW1 catalyzes the conversion of $\mathrm{m}^{1} \mathrm{G}$ to imG-14. Extracted ion chromatogram at $\mathrm{m} / \mathrm{z}$ 324.1-324.2 of the digested RNA obtained from the reaction mixtures shows that formation of the modified base requires the presence of pyruvate, SAM, and a reductant. 


\section{Figure S.5.}

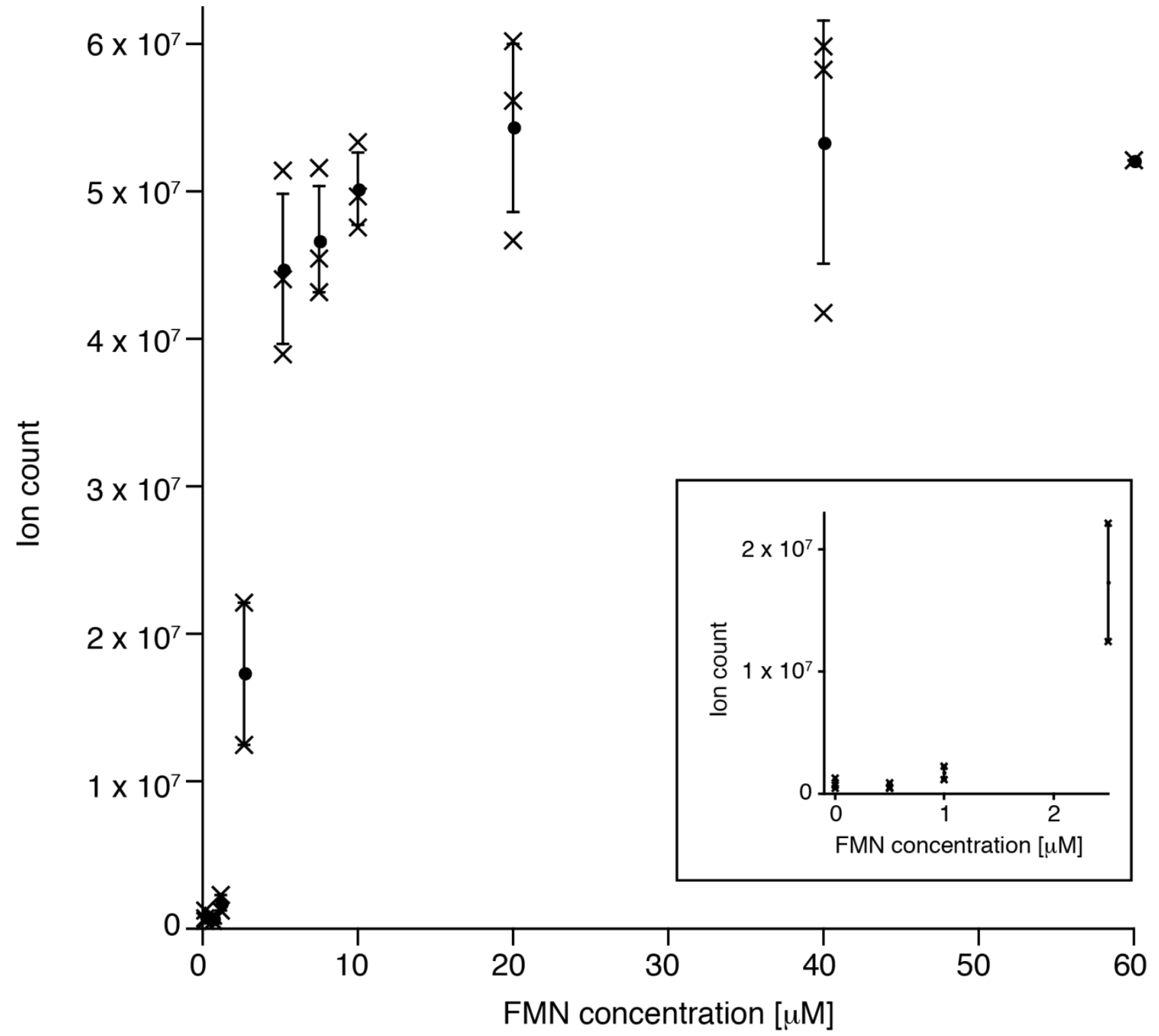

Figure S.5. The product formed by ScTYW1 after 4 hours when incubated with the following concentrations of FMN: $0,0.5,1,2.5,5,7.5,10,20,40$, and $60 \mu \mathrm{M}$. The inset panel has a smaller scale, so the data at $0,0.5,1$, and $2.5 \mu \mathrm{M}$ is visible. $\mathrm{X}$ represents the experimental data points, the dots represent the mean, and the error bars represent one standard deviation from the mean.

\section{Figure S.6.}



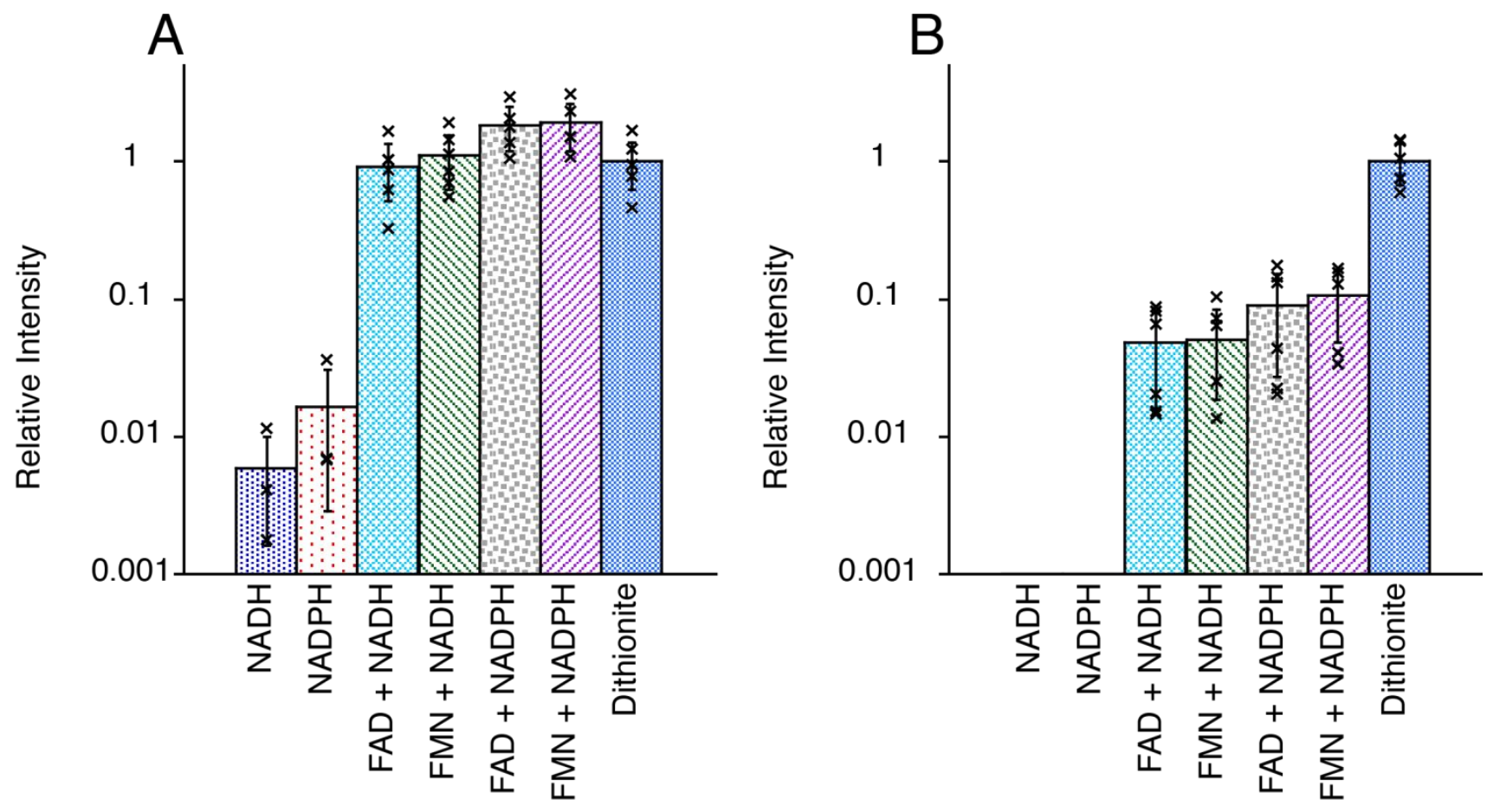

Figure S.6. A comparison of the level of product made by ScTYW1 (panel A) and MjTYW1 (panel B) with different reductants. The data were normalized to dithionite in both the $S c$ and $M j \mathrm{TYW} 1$ cases. The error bars represent one standard deviation from the mean and $\mathrm{x}$ represents the data points. 


\section{Figure S. 7.}
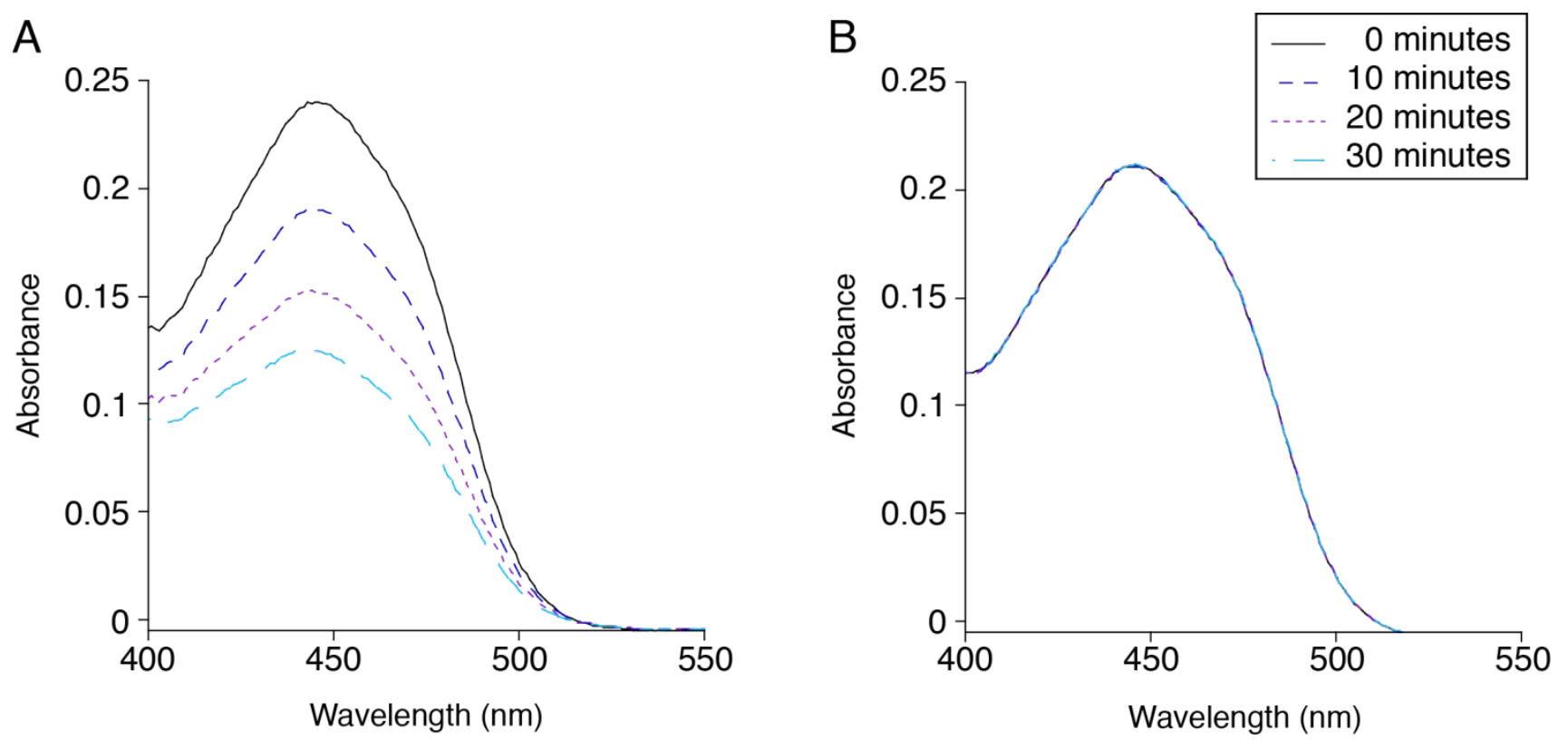

Figure S. 7. Panel A shows the absorbance spectrum between 400 and $550 \mathrm{~nm}$ of $20 \mu \mathrm{M}$ FMN when incubated with $2 \mathrm{mM}$ NADPH. Panel B shows the absorbance of $20 \mu \mathrm{M}$ FMN in the absence of pyridine nucleotide. The spectrum is shown at $0,10,20$, and $30 \mathrm{~min}$ in both cases. 


\section{References}

1. Thoden, J. B., and Holden, H. M. (2005) The Molecular Architecture of Human NAcetylgalactosamine Kinase. The Journal of Biological Chemistry 280, 32784-32791

2. Hännzelmann, P., Hernández, H. L., Menzel, C., García-Serres, R., Huynh, B. H., Johnson, M. K., Mendel, R. R., and Schindelin, H. (2004) Characterization of MOCS1A, an Oxygen-sensitive Iron-Sulfur Protein Involved in Human Molybdenum Cofactor Biosynthesis. The Journal of Biological Chemistry 279, 34721-34732

3. Studier, F. W. (2005) Protein production by auto-induction in high density shaking cultures. Protein Expr Purif 41, 207-234

4. Young, A. P., and Bandarian, V. (2018) TYW1: A Radical SAM Enzyme Involved in the Biosynthesis of Wybutosine Bases. Methods in Enzymology 606, 119-153

5. Park, J., Tai, J., Roessner, C. A., and Scott, A. I. (1996) Enzymatic Synthesis of S-Adenosyl-Lmethionine on the Preparative Scale. Bioorganic and Medicinal Chemistry 4, 2179-2185

6. Von Ehrenstein, G. (1967) Isolation of sRNA from Intact Escherichia coli Cells. Methods in Enzymology 12, 588-596 